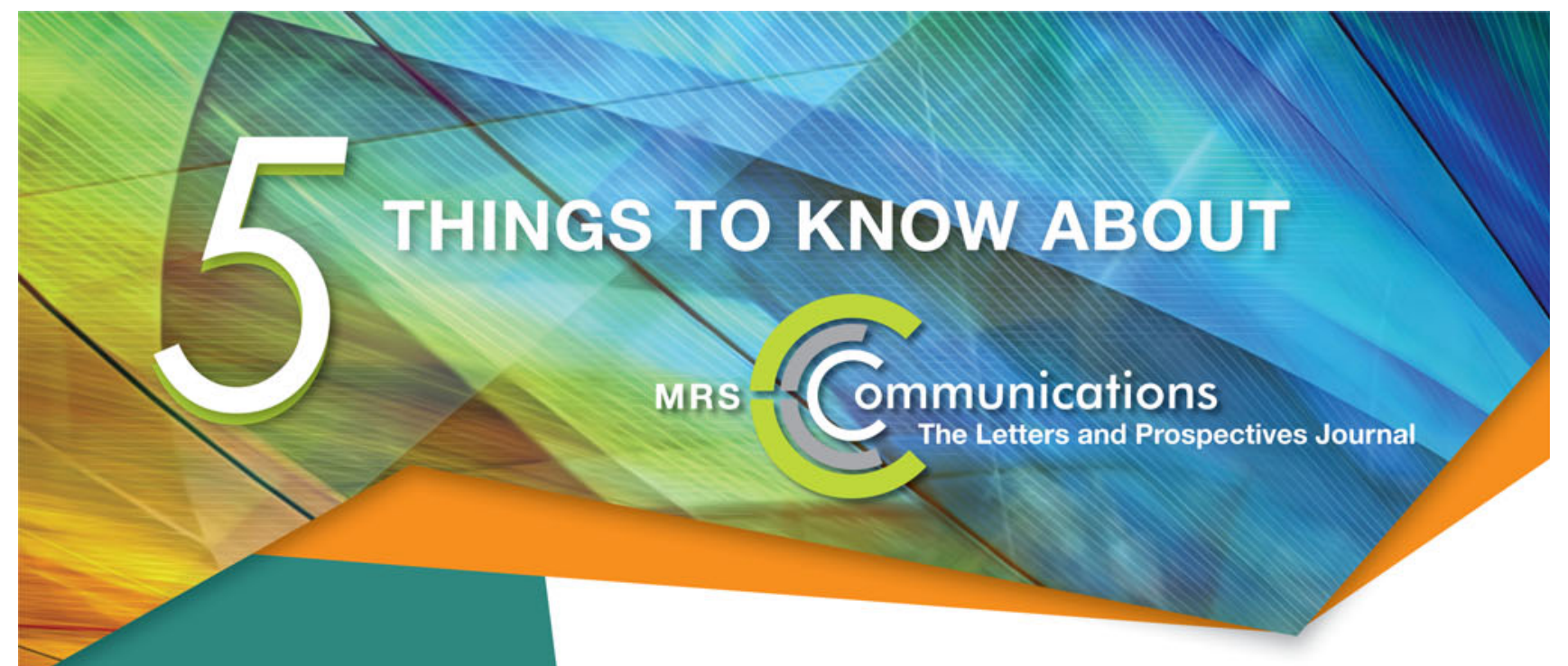

EDITOR-IN-CHIEF

Peter F. Green, University of Michigan, USA

PRINCIPAL EDITORS

Jason A. Burdick, University of Pennsylvania, USA

Luca Dal Negro, Boston University, USA

Horacio Espinosa, Northwestern University, USA

Nicola Marzari, Ecole Polytechnique

Fédérale de Lausanne, Switzerland

Paul McIntyre, Stanford University, USA

Albert Salleo, Stanford University, USA

Alec Talin, Sandia National Laboratories, USA

Nagarajan (Nagy) Valanoor, University

of New South Wales, Australia

\section{ADVISORY BOARD}

Kristi Anseth, University of Colorado, USA

A. Lindsay Greer, University of Cambridge,

United Kingdom

Supratik Guha, IBM Research, USA

Howard E. Katz, Johns Hopkins University, USA

Nicholas A. Kotov, University of Michigan, USA

Nicholas A. Kotov, University of Michigan, USA

des Mines, France

Tobin Marks, Northwestern University, USA

Linda F. Nazar, University of Waterloo, Canada

Ramamoorthy Ramesh, Oak Ridge National

Laboratory, USA

Henning Riechert, Paul-Drude-Institut

für Festkörperelektronik, Germany

Thomas P. Russell, University of Massachusetts, USA

Darrell G. Schlom, Cornell University, USA

James S. Speck, University of California,

Santa Barbara, USA

For more information about MRS Communications, visit www.mrs.org/mrc or email mrc@mrs.org.

For manuscript submission instructions,

visit www.mrs.org/mrc-instructions.

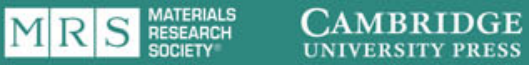

MRS Communications is publishing high-quality, rigorously reviewed materials science communications within 14 days of acceptance.

MRS Communications received its first Impact Factor (IF) from the 2012 Thomson Science Citation Index (SCl) Journal Citation Reports ${ }^{*}$ in record time-based upon only the first published issue and just one year of citations. Watch for our building success in 2014!

MRS Communications offers an Open Access publication option with, for a limited time only, a reduced article processing charge.

MRS Communications is a digital journal. Readers enjoy a variety of access options including mobile format, dynamic page-turning edition and iTunes and Android apps.

MRS Communications has published high-impact papers in its first three volumes. Look for each new issue at www.journals.cambridge.org/mrc. Prospectives articles, a unique feature of this journal, include:

Materials processing strategies for colloidal quantum dot solar cells: advances, present-day limitations and pathways to improvement

Graham H. Carey, Kang W. Chou, Buyi Yan, Ahmad R. Kirmani, Aram Amassian, Edward H. Sargent

Hairy nanoparticle assemblies as one-component functional polymer nanocomposites: opportunities and challenges Nikhil J. Fernandes, Hilmar Koerner, Emmanuel P. Giannelis, Richard A. Vaia

Recent developments in ductile bulk metallic glass composites Michael Ferry, Kevin Laws, Christopher White, David Miskovic, Karl Shamlaye, Wangiang Xu, Olga Biletska

Catalytic polymeric nanoreactors: more than a solid supported catalyst

Pepa Cotanda, Nikos Petzetakis, Rachel K. O'Reilly

Spectroscopic imaging in PFM: new opportunities for studying polarization dynamics in ferroelectrics and multiferroics

Rama Krishnan Vasudevan, Stephen Jesse, Yunseok Kim,

Amit Kumar, Sergei V. Kalinin

Biomaterials-based strategies for the engineering of mechanically active soft tissues

Zhixiang Tong and Xinqiao Jia 


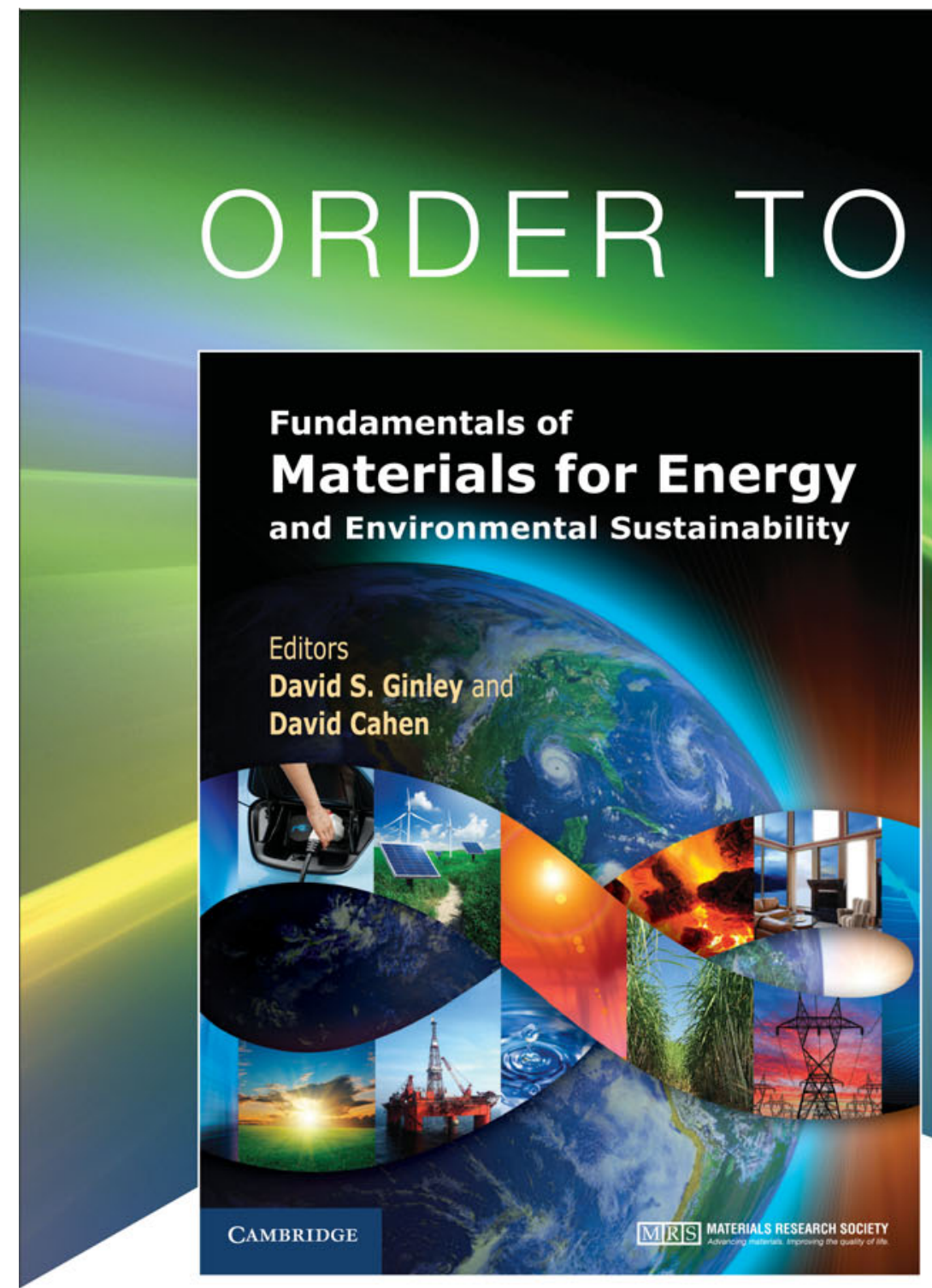

Whether you are a student taking an energy course or a newcomer to the field, this TEXTBOOK will help you understand critical relationships among environment, energy and sustainability.

Leading experts provide comprehensive coverage of each topic, bringing together diverse subject matter by integrating theory with engaging insights. Each chapter includes helpful features to aid understanding, including a historical overview to provide context, suggested further reading and questions for discussion. Every subject is beautifully illustrated and brought to life with full-color images and color-coded sections for easy browsing, making this a COMPLETE EDUCATIONAL PACKAGE.
Sections Include:

- Energy and the EnvironmentThe Global Landscape

- Nonrenewable Energy Sources

- Renewable Energy Sources

- Transportation

- Energy Efficiency

- Energy Storage, High-Penetration Renewables and Grid Stabilization
DAY!

Hardback

ISBN: 9781107000230

$\$ 79.00$ MRS Member Price $\$ 99.00$ List Price

www.mrs.org/energybook 


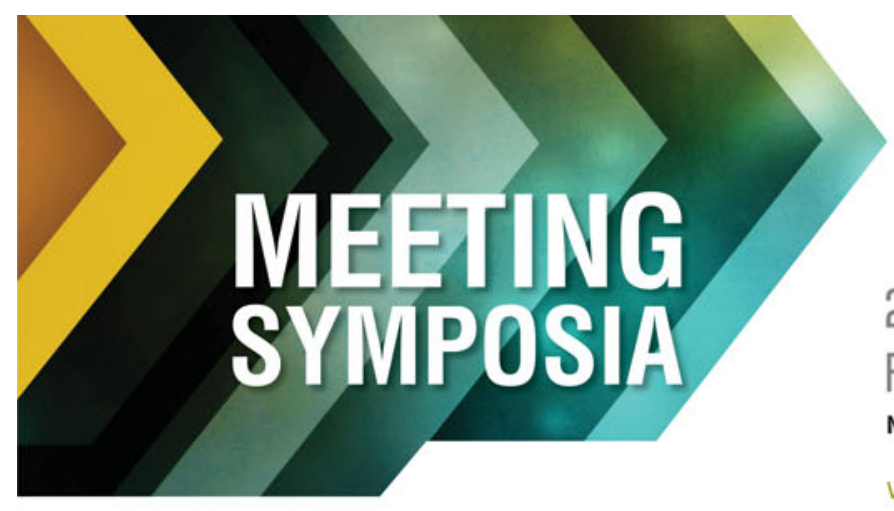

\section{$2014 \mathrm{M} \mid \mathrm{R} / \mathrm{S}$ FALL MEETING \& EXHIBIT}

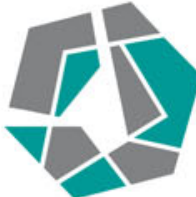

November 30 - December 5, 2014 | Boston, Massachusetts

www. mrs. org/fall2014

BIOMATERIALS AND SOFT MATERIALS

A Organic Bioelectronics

B Multifunctional Polymeric and Hybrid Materials

Medical Applications of Noble Metal Nanoparticles (NMNPs)

Materials and Concepts for Biomedical Sensing

Hard-Soft Interfaces in Biological and Bioinspired MaterialsBridging the Gap between Theory and Experiment

F Reverse Engineering of Bioinspired Nanomaterials

G Plasma Processing and Diagnostics for Life Sciences

H Micro/Nano Engineering and Devices for Molecular and Cellular Manipulation, Stimulation and Analysis

Emerging $1 \mathrm{D}$ and $2 \mathrm{D}$ Nanomaterials in Health Care

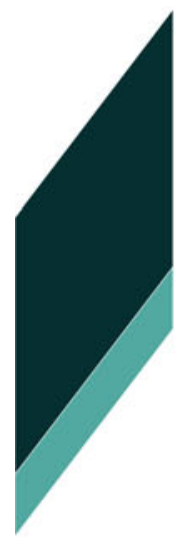

\section{ELECTRONICS AND PHOTONICS}

$J$ Emerging Non-Graphene 2D Atomic Layers and van der Waals Solids

K Graphene and Graphene Nanocomposites

L Optical Metamaterials and Novel Optical Phenomena Based on Nanofabricated Structures

M Materials and Technology for Nonvolatile Memories

$\mathrm{N}$ Frontiers in Complex Oxides

0 Oxide Semiconductors

P Hybrid Oxide/Organic Interfaces in Organic Electronics

Q Fundamentals of Organic SemiconductorsSynthesis, Morphology, Devices and Theory

R Diamond Electronics and Biotechnology-Fundamentals to Applications

\section{ENERGY AND SUSTAINABILITY}

S Advances in Materials Science, Processing and Engineering for Fuel Cells and Electrolyzers

T Wide-Bandgap Materials for Solid-State Lighting and Power Electronics

U Organic Photovoltaics-Fundamentals, Materials and Devices

V Sustainable Solar-Energy Conversion Using Earth-Abundant Materials

W Perovskite-Based and Related Novel Material Solar Cells

Y Technologies for Grid-Scale Energy Storage

Z Materials Challenges for Energy Storage across Multiple Scales

AA Synthesis, Processing and Mechanical Properties of Functional Hexagonal Materials for Energy Applications

BB Molecular, Polymer and Hybrid Materials for Thermoelectrics

CC Advanced Materials and Devices for Thermoelectric Energy Conversion

DD Materials for Advanced Nuclear Technologies

EE Scientific Basis for Nuclear Waste Management XXXVII

FF Materials as Tools for Sustainability

\section{NANOMATERIALS AND SYNTHESIS}

GG Nanomaterials for Harsh Environment Sensors and Related Electronic and Structural ComponentsDesign, Synthesis, Characterization and Utilization

HH Flame and High-Temperature Synthesis of Functional NanomaterialsFundamentals and Applications

II Semiconductor Nanocrystals, Plasmonic Metal Nanoparticles, and Metal-Hybrid Structures

JJ 3D Mesoscale ArchitecturesSynthesis, Assembly, Properties and Application

KK Directed Self-Assembly for Nanopatterning

LL. Semiconductor Nanowires - Growth, Physics, Devices, and Applications MM Carbon Nanotubes-Synthesis, Properties, Functionalization and Applications

THEORY, CHARACTERIZATION AND MODELING

NN Mathematical and Computational Aspects of Materials Science

00 In Situ Characterization of Dynamic Processes during Materials Synthesis and Transformation

PP Advances in Scanning Probe Microscopy for Multimodal Imaging at the Nanoscale

QQ Advances in Nanoscale Subsurface, Chemical and Time-Resolved Studies of Soft Matter

RR Scaling Effects in PlasticitySynergy between Simulations and Experiments

SS Informatics and Genomics for Materials Development

IT Advanced Materials Exploration with Neutrons and X-RaysThe State-of-the-Art in the International Year of Crystallography

\section{GENERAL}

UU Structure-Property Relations in Amorphous Solids

W Reactive Materials-Past, Present and Future

WW Defects and Radiation Effects in Advanced Materials

XX Bridging Scales in Heterogeneous Materials

YY Advanced Structural and Functional Intermetallic-Based Alloys

ZZ Hierarchical, High-Rate, Hybrid and Roll-to-Roll Manufacturing

AAA Undergraduate Research in Materials Science-Impacts and Benefits

\section{Meeting Chairs}

Husam N. Alshareef King Abdullah University of Science and Technology Amit Goyal Oak Ridge National Laboratory

Gerardo Morell University of Puerto Rico

José A. Varela University of Săo Paulo State - UNESP

In Kyeong Yoo Samsung Advanced Institute of Technology

\section{R S MATERIALS RESEARCH SOCIETY}

506 Keystone Drive • Warrendale, PA 15086-7573 Tel $724.779 .3003 \cdot$ Fax 724.779 .8313

info@mrs.org • www.mrs.org
Don't Miss This Future MRS Meeting! 2015 Mrs Spring Meeting \& Exhibit April 6-10, 2015 Moscone West \& San Francisco Marriott Margu

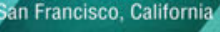




\title{
MATERIALS RESEARCH SOCIETY
}

\section{Board of Directors Officers}

Tia Benson Tolle, President

Orlando Auciello, Immediate Past President

Oliver Kraft, Vice President/President-Elect

Sean J. Hearne, Secretary

Michael R. Fitzsimmons, Treasurer

Todd M. Osman, Executive Director

\section{Directors}

Shenda M. Baker

Alexandra Boltasseva

C. Jeffrey Brinker

David Cahen

Stephen J. Eglash

Chang-Beom Eom

Susan Ermer

Eric Garfunkel
Sossina M. Haile

Andrea M. Hodge

Hideo Hosono

Fiona C. Meldrum

Kornelius Nielsch

Eric A. Stach

Stephen K. Streiffer

Loucas Tsakalakos

\section{Publications Committee}

\author{
R.A. Vaia, Chair
}

TBD, Editors Subcommittee

A.J. Hurd, New Publication Products Subcommittee

J.M. Phillips, Publications Quality Subcommittee

\section{MRS Committee Chairs}

Bruce M. Clemens, Academic Affairs

C.B. Carter, Awards

N. Bassim, Government Affairs

D.S. Ginley, Meetings Committee

\section{MRS Headquarters}

T.M. Osman, Executive Director

J.A. Dillen, Director of Finance and Administration

P.A. Hastings, Director of Meeting Activities

E.K. Novak, Director of Communications

\section{About the Materials Research Society}

The Materials Research Society (MRS) is a not-for-profit scientific association founded in 1973 to promote interdisciplinary goal-oriented basic research on materials of technological importance. Membership in the Society includes almost 16,000 scientists from industrial, government, and university research laboratories in the United States and abroad.

The Society's interdisciplinary approach to the exchange of technical information is qualitatively different from that provided by single-discipline professional societies because it promotes technical exchange across the various fields of science affecting materials development. MRS sponsors three major international annual meetings encompassing many topical symposia, as well as numerous single-topic scientific meetings each year. It recognizes professional and technical excellence, conducts tutorials, and fosters technical exchange in various local geographical regions through Section activities and Student Chapters on university campuses.
Y. Chabal, Member Engagement

R.A. Vaia, Publications

A. Risbud, Public Outreach
MRS publishes symposia proceedings, the MRS Bulletin, and other volumes on current scientific developments. The Journal of Materials Research, the archival journal spanning fundamental developments in materials science, is published twenty-four times a year by Cambridge University Press for the MRS.

MRS Communications is a full-color letters and prospectives journal focused on groundbreaking work across the spectrum of materials research.

MRS is an Affiliated Society of the American Institute of Physics and participates in the international arena of materials research through associations with professional organizations such as the International Union of Materials Research Societies.

For further information on the Society's activities, contact MRS Headquarters, 506 Keystone Drive, Warrendale, PA 15086-7573; telephone (724) 779-3003; fax (724) 779-8313. 
A publication of the

mrs Communications

MRSS MATERIALS RESEARCH SOCIETY

CAMBRIDGE

For further information about this journal please UNIVERSITY PRESS 